\title{
Effect of Oromotor Stimulation on Sucking and Feeding Performance of Preterm Neonates Admitted in Neonatal Care Unit of Selected Hospital, West Bengal
}

\author{
Ishika Roy ${ }^{1}$, Manasi Jana ${ }^{2}$ \\ ${ }^{1}$ Lecturer, Neotia Academy of Nursing, Kolkata, West Bengal, India. \\ ${ }^{2}$ Professor, College of Nursing, NRS Medical College and Hospital, Kolkata, West Bengal, India. \\ Corresponding Author: Ishika Roy
}

\section{ABSTRACT}

Feeding problem remains a common problem among preterm neonates. An experimental study was undertaken to assess the effect of oromotor stimulation on feeding and sucking performance of preterm neonates admitted in selected hospital, west Bengal. Quasi experimental time series design was adopted. From the population of preterm neonates 60 samples (30 in experimental group and 30 in control group) were selected by non-probability purposive sampling. After selection, initially the baseline data was collected using a record analysis proforma. On the $1^{\text {st }}$ day sucking and feeding performance scoring was done before giving the oromotor stimulation to ascertain the homogeneity of the experimental and control group. After that in two consecutive feeding, oromotor stimulation was given to the neonates in experimental group before 15 minutes of the feeding. The intervention was given to the neonates in experimental group for the next two days, twice only in two consecutive feeding. Neonates in control group received routine care. Sucking and feeding performance scoring was done in both groups using a standardized non-nutritive sucking scoring scale and a validated and reliable early feeding performance scale. The result showed that there is significant difference in sucking performance $(\mathrm{t}=3.60, \quad \mathrm{p}<0.05)$ and feeding performance $(\mathrm{t}=3.78, \quad \mathrm{p}<0.05)$ among experimental and control group in final observation. It can be concluded that oromotor stimulation is effective to improve the feeding and sucking abilities of
\end{abstract}

preterm neonates. In the neonatal care units, nurses can provide oromotor stimulation to improve feeding and sucking abilities of the preterm neonates.

Keywords: Feeding, Sucking, Performance, Preterm, Oromotor stimulation, Neonates, Preterm neonates

\section{INTRODUCTION}

According to WHO, every year about 15 million babies are born prematurely around all over the world and that is more than one in 10 of all babies born globally. Almost 1 million children die each year due to complications of the preterm birth. In India out of the total 27 million babies who born every year, 3.5 million babies are premature. India is the country with the greatest number of preterm births. [1]

The transition from gavage to independent oral feeding is a challenge to preterm neonates and those who care for them. Infants who face these difficulties often require prolonged hospitalization that may in turn lead to maternal stress and financial burden. ${ }^{[2]}$

The effects of early oral motor difficulties on breast feeding and the length of hospital stay underline the significance of the need to improve the normal development of the oral motor structures. ${ }^{[3]}$ Various intervention techniques are used by 
nutritionists to improve the oral feeding performance of premature infants. Effect of some of the interventions has been previously proved. For example, cheek/chin support during the feeding time increases the intake volume ${ }^{[4]}$ and an auditory-tactilevisual-vestibular program speeds up the transition time to independent oral feeding, reducing hospital stay.

In the year 2018 a study was conducted by Pareshkumar A. et al. which showed that oral tactile stimulation with non-nutritive sucking for 5-10 minutes before oral feeds helps to reduce feeding difficulties for preterm neonates. ${ }^{[6]}$ In the year 2012 Lau C, Fucile S, Gisel EG. conducted a study which showed the number of days to reach oral feeding in preterm babies was decreased by oral motor stimulation, which in turn conferred earlier hospital discharge. ${ }^{[7]}$

Non-nutritive sucking during tube feeding appears to improve the rate of intake during feeding and has been reported to shorten the transition time to exclusive oral feeding. ${ }^{[8]}$ A study conducted by Bala P, Kaur R, Mukhopadhyay K et al. revealed that non- nutritive sucking for 5 to 10 minutes before oral feeds appears to improve feeding performance, physiological stability during feeds and volume consumed during feeds. ${ }^{[9]}$ They concluded that Premature Infant Oral Motor Intervention (PIOMI) found as a useful method for preterm neonates and PIOMI should be integrated in feeding rehabilitation programs of the preterm neonates born with gestational age of 26-29 weeks. ${ }^{[10]}$

Oromotor stimulation found to be effective in improving the sucking frequency, latch scores and fastens the transition time from spoon feeding to breast feeding. ${ }^{[1]]}$ The non-nutritive sucking improves the sucking rhythm, strength and the number of sucking bursts accomplished by babies. ${ }^{[12]}$ The Non- nutritive sucking is normally performed using the little finger gloved. This technique is found to be effective to promote proper coordination on sucking, swallowing and breathing. This also improves neonate's maturation process and muscles coordination used in sucking. ${ }^{[13]}$ The Non-nutritive sucking with gloved finger and oral motor stimulation enhance the responses of oral reflexes, the neonatal sucking pattern and the contributes to exclusive breastfeeding. ${ }^{[14]}$ Oromotor stimulation along with non-nutritive sucking improves sucking performance among neonates having feeding deficiencies and helps in earlier initiation of nutritive sucking and promotion of sustained nutritive sucking activities, ${ }^{[15]}$

Nurses are the primary caregivers of preterm neonates admitted in neonatal care units. They can serve a significant role in enhancing the sucking and feeding performance of preterm neonates to achieve full oral feeding as earlier as possible. ${ }^{[16]}$ Effect of oral stimulation on sucking and feeding performance was already proved still investigator intended to find out in the different setting. With this conception and being a nursing personnel, the Investigator wanted to conduct a study on effect of oromotor stimulation on sucking and feeding performance of preterm neonates admitted in neonatal care unit of selected hospital, West Bengal.

\section{MATERIALS AND METHODS}

Experimental time series design was adopted for the research study. Following institutional ethical committee approval, 60 neonates were selected by Non probability purposive sampling technique from NICU, out of which 30 neonates were assigned in experimental group and the rest 30 neonates in control group. Preterm neonates born between 28-32 weeks of gestation who were having orogastric tube feeding were selected for the study. Neonates who were on respiratory support and had congenital anomalies affecting feeding and digestive function had been excluded. Study procedure was explained and consent was taken from the mothers of the neonates before data collection. Socio-demographic information about the neonates in both experimental and control group was 
collected during enrollment using a record analysis proforma. Pre-interventional sucking and feeding performance of the neonates in both experimental and control group was assessed initially at enrollment. Pre-feeding oromotor stimulation was performed for the neonates in the experimental group before 15 minutes of the two consecutive feedings for the three consecutive days. Neonates in the control group received routine care only. Post-test feeding and sucking performance of the neonates in both the groups were assessed during and after each of the feeding. Feeding performance of the neonates was assessed by using early feeding performance scoring scale. The tool was modified from the Early feeding skill assessment Likert scale which is a standardized tool (developed by S. Thoyre). The scale has broad areas like oral feeding readiness, oral feeding skill and oral feeding recovery. The early feeding performance scale had a total of 18 items. The minimum possible score was ' 0 ' and the maximum possible score was ' 40 '. The tool was validated from 6 experts from Child Health Nursing specialty and 1neonatologist. The Reliability of the tool was established using Cronbach's alpha method where the reliability was found to be 0.93. Sucking performance of the neonates was assessed by Non-nutritive sucking scoring scale, which was a standardized tool developed by Neiva FC, et al. ${ }^{[17]}$ The tool had a total of 12 items among which 9 are positive items and other 3 items are negative items. In accordance to the tool the sucking performance was classified as, poor sucking performance (score < 33), moderate sucking performance (score 33-49), good sucking performance (score 50 or above). Pilot study was conducted before conducting the main study and the study was found to be feasible.

\section{Statistical methods}

Analysis and interpretation of data were done in accordance with the objectives of the study using descriptive and inferential statistics. Master data sheet was prepared according to the performance of the participants. Demographic characteristics computed in frequency and percentage. The ' $t$ ' test values were computed to find out the effect of oromotor stimulation on feeding and sucking performance.

\section{RESULTS}

Table - I: Description of the demographic data, $\mathrm{n}=60(\mathrm{nE}=30+\mathrm{nC}=30), \mathrm{E}=$ experimental group, $\mathrm{C}=$ control group

\begin{tabular}{|l|l|l|l|l|}
\hline Sample characteristics & \multicolumn{3}{|l|}{ Experimental group } & \multicolumn{2}{l|}{ Control group } \\
\hline \multirow{3}{*}{ Age (in days) } & Frequency & percentage & Frequency & percentage \\
\cline { 2 - 5 } 0-3 days & & & & \\
4-7 days & 18 & 60 & 21 & 70 \\
\hline Sex & 12 & 40 & 9 & 30 \\
\hline Boy & & & & \\
\hline Girl & 11 & 36.67 & 16 & 53.33 \\
\hline Gestational age: & 19 & 63.33 & 14 & 46.67 \\
\hline $27-29$ weeks & & & & \\
\hline $30-32$ weeks & 16 & 53.33 & 17 & 56.67 \\
\hline Birth weight: - & 14 & 46.67 & 13 & 43.33 \\
\hline $1000-1199$ grams & 18 & & & \\
\hline $1200-1399$ grams & 10 & 60 & 16 & 53.33 \\
\hline $1400-1599$ grams & 2 & 33.33 & 14 & 36.67 \\
\hline Type of feeding: - & & 6.67 & & 10 \\
\hline Expressed breast milk & 22 & & & \\
\hline Artificial feeding & 8 & 73.33 & 20 & 66.67 \\
\hline
\end{tabular}

Data presented in table 1 showed that the majority of the neonates in both experimental group $(60 \%)$ and control group $(70 \%)$ belonged to the age group of 0 3 days. $63.33 \%$ neonates in experimental group were girl whereas $53.33 \%$ neonates in control group were boy. More than average of the neonates in both experimental group $(53.33 \%)$ and control group $(56.67 \%)$ belonged to the gestational age group of 27- 
Ishika Roy et.al. Effect of oromotor stimulation on sucking and feeding performance of preterm neonates admitted in neonatal care unit of selected hospital, West Bengal.

29 weeks. More than half of the neonates in both experimental group $(60 \%)$ and control group $(53.33 \%)$ had a birth weight of 1000 1199 grams. Majority of the neonates that is $73.33 \%$ and $66.67 \%$ in experimental group and control group respectively was on expressed breast milk.

Table 2: mean, SD and unpaired ' $t$ ' value of pre-intervention sucking performance score observed by NNS scoring scale in experimental and control group, $\mathrm{n}=60(\mathrm{nE}=30+\mathrm{nC}=30)$, $\mathbf{E}=$ experimental group, $\mathrm{C}=$ control group

\begin{tabular}{|l|l|l|l|l|}
\hline Time & Group & Mean & SD & $\begin{array}{l}\text { 't' } \\
\text { value }\end{array}$ \\
\hline $\begin{array}{l}\text { Pre- } \\
\text { interventional }\end{array}$ & $\begin{array}{l}\text { Experimental } \\
\text { group }\end{array}$ & 23.63 & 3.42 & \multirow{2}{*}{1.01} \\
\hline & Control group & 22.76 & 3.28 & \\
\hline
\end{tabular}
Table value of $t d f(58)=2.05, P<0.05$

Data presented in table 2 showed that there is no significant difference in the pre-intervention sucking performance of experimental and control group as evident by ' $t$ ' value. So, the group was homogenous in terms of sucking performance.

Table 3: mean, SD and unpaired ' $t$ ' value of pre-intervention feeding performance score observed by EFS scoring scale in experimental and control group, $n=60(\mathrm{nE}=30+\mathrm{nC}=30)$, $\mathrm{E}=$ experimental group, $\mathrm{C}=$ control group

\begin{tabular}{|l|l|l|l|l|}
\hline Time & Group & Mean & SD & $\begin{array}{l}\text { 't' } \\
\text { value }\end{array}$ \\
\hline $\begin{array}{l}\text { Pre- } \\
\text { interventional }\end{array}$ & $\begin{array}{l}\text { Experimental } \\
\text { group }\end{array}$ & 18.4 & 3.65 & \multirow{2}{*}{0.14} \\
\hline & Control group & 18.27 & 3.43 & \\
\hline
\end{tabular}

Table value of $t$ df $(58)=2.05, P<0.05$

Data presented in table 3 showed that there is no significant difference in the pre-intervention feeding performance of experimental and control group as evident by ' $t$ ' value. So, the group was homogenous in terms of feeding performance.

Table 4: Frequency and percentage distribution of preterm neonates assigned in experimental group according to post-test sucking performance, as measured by non-nutritive sucking scoring scale. $\mathrm{nE}=30$ ( $\mathrm{E}=\mathrm{experimental}$ group)

\begin{tabular}{|c|c|c|c|c|c|c|}
\hline \multirow{3}{*}{ Level of sucking performance } & \multicolumn{2}{|c|}{ Sucking performance on day 1} & \multicolumn{2}{|c|}{ Sucking performance on day 2} & \multicolumn{2}{|c|}{ Sucking performance on day 3} \\
\hline & $\mathbf{1}^{\text {st }}$ feed & $2^{\text {nd }}$ feed & $1^{\text {st }}$ feed & $2^{\text {nd }}$ feed & $1^{\text {st }}$ feed & $2^{\text {nd }}$ feed \\
\hline & $\operatorname{Fr}(\%)$ & $\operatorname{Fr}(\%)$ & $\operatorname{Fr}(\%)$ & $\operatorname{Fr}(\%)$ & $\operatorname{Fr}(\%)$ & $\operatorname{Fr}(\%)$ \\
\hline Poor $(<33)$ & $30(100)$ & $30(100)$ & $17(56.67)$ & $11(36.67)$ & $0(0)$ & $0(0)$ \\
\hline Moderate (33-49) & $0(0)$ & $0(0)$ & $13(43.33)$ & $19(63.33)$ & $23(76.67)$ & $19(63.33)$ \\
\hline Good (50 and above) & $0(0)$ & $0(0)$ & $0(0)$ & $0(0)$ & $7(23.33)$ & $11(36.67)$ \\
\hline
\end{tabular}

Data presented in table 4 showed that, on day 1 in both $1^{\text {st }}$ and $2^{\text {nd }}$ feeding all the neonates had poor sucking performance whereas, on day $3,2^{\text {nd }}$ feeding performance showed most of the neonates $63.33 \%$ had moderate sucking performance and $36.67 \%$ had good sucking performance.

Table 5: Frequency and percentage distribution of preterm neonates assigned in control group according to post-test sucking performance, as measured by nonnutritive sucking scoring scale. $\mathrm{nC}=30$ ( $\mathrm{C}=$ control group)

\begin{tabular}{|c|c|c|c|c|c|c|}
\hline \multirow[t]{3}{*}{ Level of sucking performance } & \multicolumn{2}{|c|}{ Sucking performance on day 1} & \multicolumn{2}{|c|}{ Sucking performance on day 2} & \multicolumn{2}{|c|}{ Sucking performance on day 3} \\
\hline & $\mathbf{1}^{\text {st }}$ feed & $2^{\text {nd }}$ feed & $1^{\text {st }}$ feed & $2^{\text {nd }}$ feed & $1^{\text {st }}$ feed & $2^{\text {nd }}$ feed \\
\hline & $\operatorname{Fr}(\%)$ & $\operatorname{Fr}(\%)$ & $\operatorname{Fr}(\%)$ & $\operatorname{Fr}(\%)$ & $\operatorname{Fr}(\%)$ & $\operatorname{Fr}(\%)$ \\
\hline Poor $(<33)$ & $30(100)$ & $30(100)$ & $24(80)$ & $20(66.67)$ & $1(3.33)$ & $1(3.33)$ \\
\hline Moderate (33-49) & $0(0)$ & $0(0)$ & $6(20)$ & $10(33.33)$ & $29(96.67)$ & $27(90)$ \\
\hline Good (50 and above) & $0(0)$ & $0(0)$ & $0(0)$ & $0(0)$ & $0(0)$ & $2(6.67)$ \\
\hline
\end{tabular}

Table 6: mean, SD and paired ' $t$ ' value of sucking score by NNS scoring scale in experimental group, $n E=30(E=e x p e r i m e n t a l$ group)

\begin{tabular}{|l|l|l|l|l|}
\hline Time & Mean & SD & MD & 't' value \\
\hline Pre intervention & 23.63 & 3.42 & 0.4 & 0.47 \\
Day 1 $\left(1^{\text {st }}\right.$ feeding) & 24.03 & 3.16 & & \\
\hline Pre intervention & 23.63 & 3.42 & 1.24 & 1.40 \\
Day 1 $\left(2^{\text {nd }}\right.$ feeding) & 24.87 & 3.42 & & \\
\hline Pre intervention & 23.63 & 3.42 & 8.53 & $8.29\left(^{*}\right)$ \\
Day 2 $\left(1^{\text {st }}\right.$ feeding) & 32.16 & 4.48 & & \\
\hline Pre intervention & 23.63 & 3.42 & 11.7 & $10.01\left(^{*}\right)$ \\
Day 2 $\left(2^{\text {nd }}\right.$ feeding) & 35.33 & 5.41 & & \\
\hline Pre intervention score & 23.63 & 3.42 & 20.87 & $17.71\left(^{*}\right)$ \\
Day 3 $\left(1^{\text {st }}\right.$ feeding) & 44.5 & 5.47 & & \\
\hline Pre intervention & 23.63 & 3.42 & 23.2 & $18.82\left(^{*}\right)$ \\
Day 3 $\left(2^{\text {nd }}\right.$ feeding & 46.83 & 5.82 & & \\
\hline
\end{tabular}


Ishika Roy et.al. Effect of oromotor stimulation on sucking and feeding performance of preterm neonates admitted in neonatal care unit of selected hospital, West Bengal.

Data presented in table 5 showed that, on day 1 in both 1 st and 2 nd feeding all the neonates had poor sucking performance. On day 3 , the 2 nd feeding performance of most of the neonates $(90 \%)$ had moderate sucking performance and only $3.33 \%$ neonates had poor sucking performance.

Data presented in table 6 showed that there is significant difference between the mean pre-test sucking performance score and post-test sucking performance score of preterm neonates in experimental group after receiving oromotor stimulation on day 2, in 1st and 2nd feeding, and day 3, in 1 st and 2nd feeding. It can be concluded that oromotor stimulation is effective in improving the sucking performance of preterm neonates.

Table 7:comparison of mean, SD and paired ' $t$ ' value of sucking score by NNS scoring scale in experimental group and control group, $\mathrm{n}=60(\mathrm{nE}=30+\mathrm{nC}=30), \mathrm{E}=$ experimental group, $\mathrm{C}=$ control group

\begin{tabular}{|l|l|l|l|l|l|}
\hline Time & Group & Mean & SD & MD & 't' value \\
\hline Day 1 & Experimental group & 24.03 & 3.16 & 0.98 & 0.59 \\
$\left(1^{\text {st }}\right.$ feeding $)$ & Control group & 23.5 & 3.78 & & \\
\hline Day 1 & Experimental group & 24.87 & 3.42 & 0.94 & 1.01 \\
$\left(2^{\text {nd }}\right.$ feeding $)$ & Control group & 23.93 & 3.78 & & \\
\hline Day 2 & Experimental group & 32.16 & 4.48 & 2.3 & 1.94 \\
$\left(1^{\text {st }}\right.$ feeding $)$ & Control group & 29.86 & 4.69 & & \\
\hline Day 2 & Experimental group & 35.33 & 5.41 & 3.46 & $2.63\left(^{*}\right)$ \\
$\left(2^{\text {nd }}\right.$ feeding $)$ & Control group & 31.87 & 4.73 & & \\
\hline Day 3 & Experimental group & 44.5 & 5.47 & 5.27 & $3.74\left(^{*}\right)$ \\
$\left(1^{\text {st }}\right.$ feeding $)$ & Control group & 39.23 & 5.44 & & \\
\hline Day 3 & Experimental group & 46.83 & 5.82 & 5.47 & $3.60\left(^{*}\right)$ \\
$\left(2^{\text {nd }}\right.$ feeding $)$ & Control group & 41.36 & 5.94 & & \\
\hline
\end{tabular}

Data presented in table 7 showed that there is significant difference between the mean post-test sucking performance score of preterm neonates in experimental group and that of preterm neonates in control group as measured by non-nutritive sucking scoring scale on day 2 in 2 nd feeding and on day 3 in 1 st and 2 nd feeding as evident from $t$ value at 0.05 level of significance.. So, oromotor stimulation found to be effective in improving the sucking performance of preterm neonates.

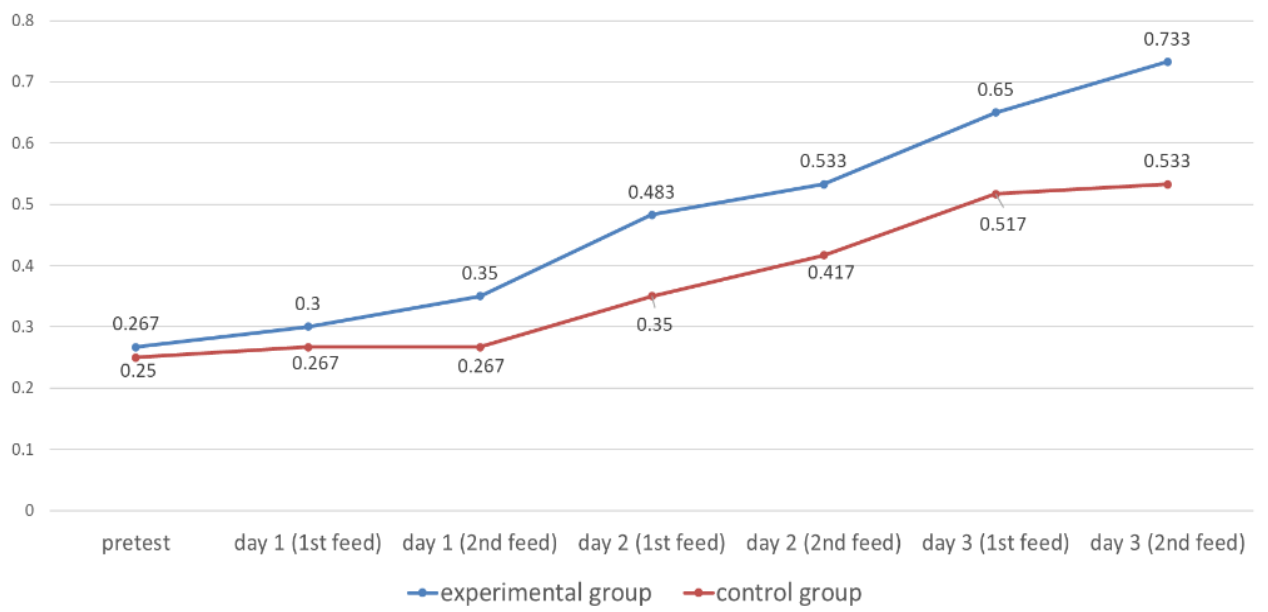

Figure 1: Line diagram showing mean oral feeding readiness score of the preterm neonates in experimental and control group, $\mathbf{n}=$ $60(n E=30+n C=30), E=$ experimental group, $C=$ control group

Data in line diagram showed that mean oral feeding readiness score in both experimental and control groups have consistently increased over time but the score in experimental group is higher than that of the control group 
Ishika Roy et.al. Effect of oromotor stimulation on sucking and feeding performance of preterm neonates admitted in neonatal care unit of selected hospital, West Bengal.

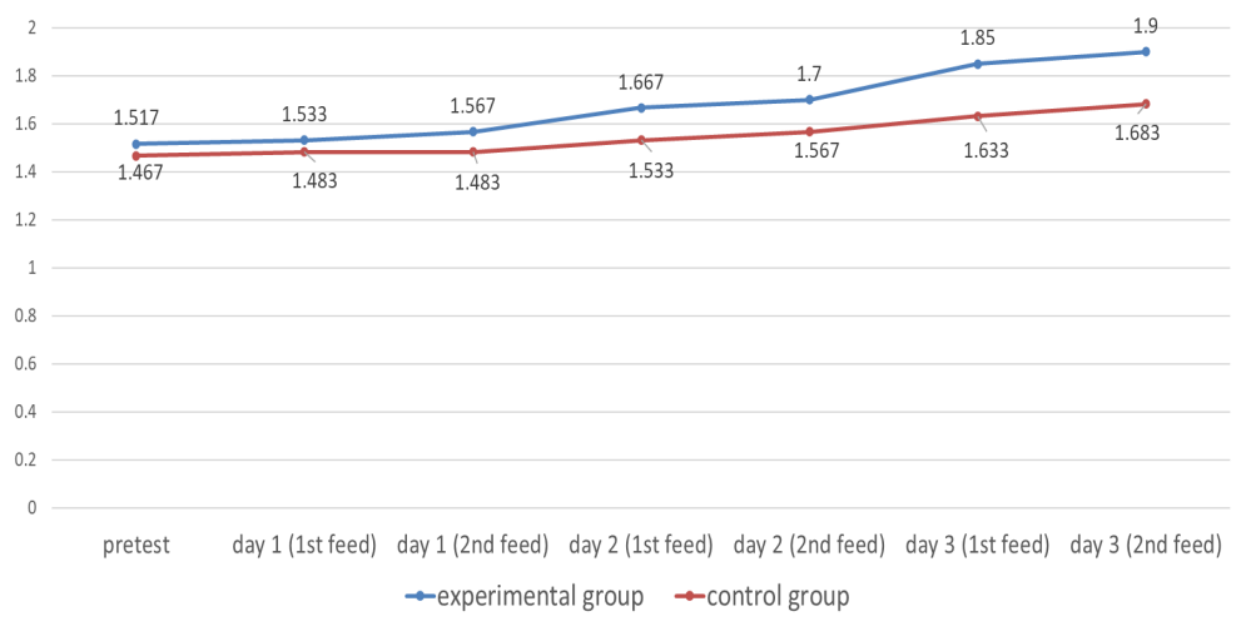

Figure 2: line diagram showing mean score of ability to remain engage in feeding in the preterm neonates in experimental and control group, $\mathrm{n}=60(\mathrm{nE}=30+\mathrm{nC}=30), \mathrm{E}=$ experimental group, $\mathrm{C}=$ control group

Data in the line diagram showed that mean score of ability to remain engage in feeding in experimental group is higher than that of the control group.

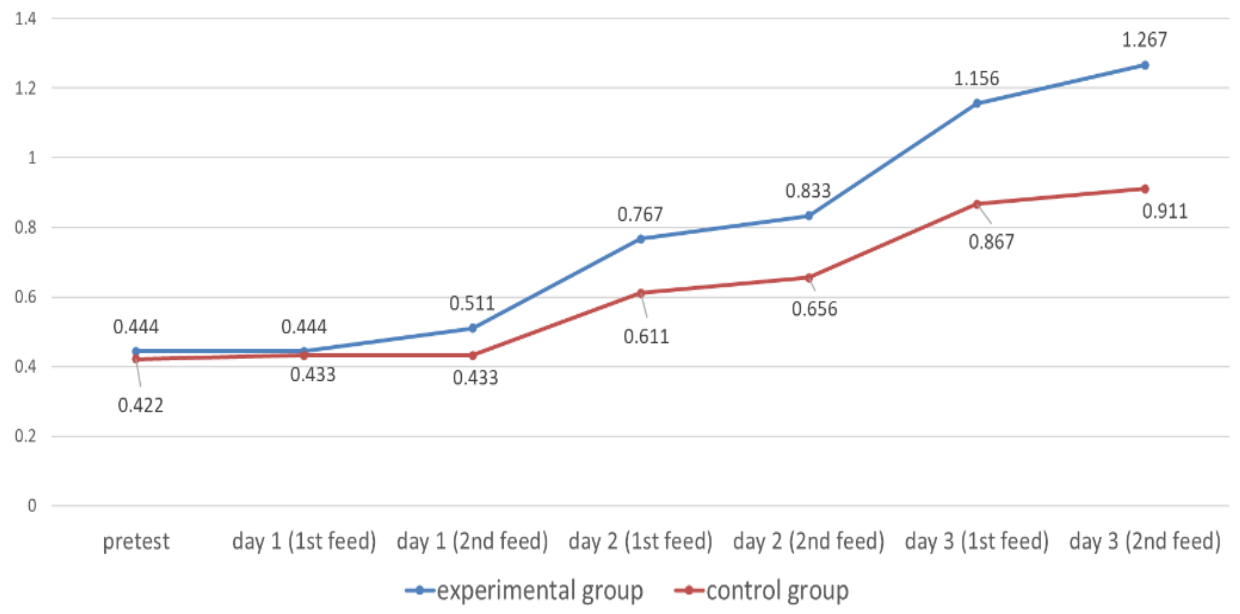

Figure 3: line diagram shows mean score of ability to organize oral motor functioning in the preterm neonates in experimental and control group, $\mathrm{n}=60(\mathrm{nE}=30+\mathrm{nC}=30), \mathrm{E}=$ experimental group, $\mathrm{C}=$ control group

Data in line diagram showed that mean score of ability to organize oral motor functioning in experimental group is higher than that of the control group.

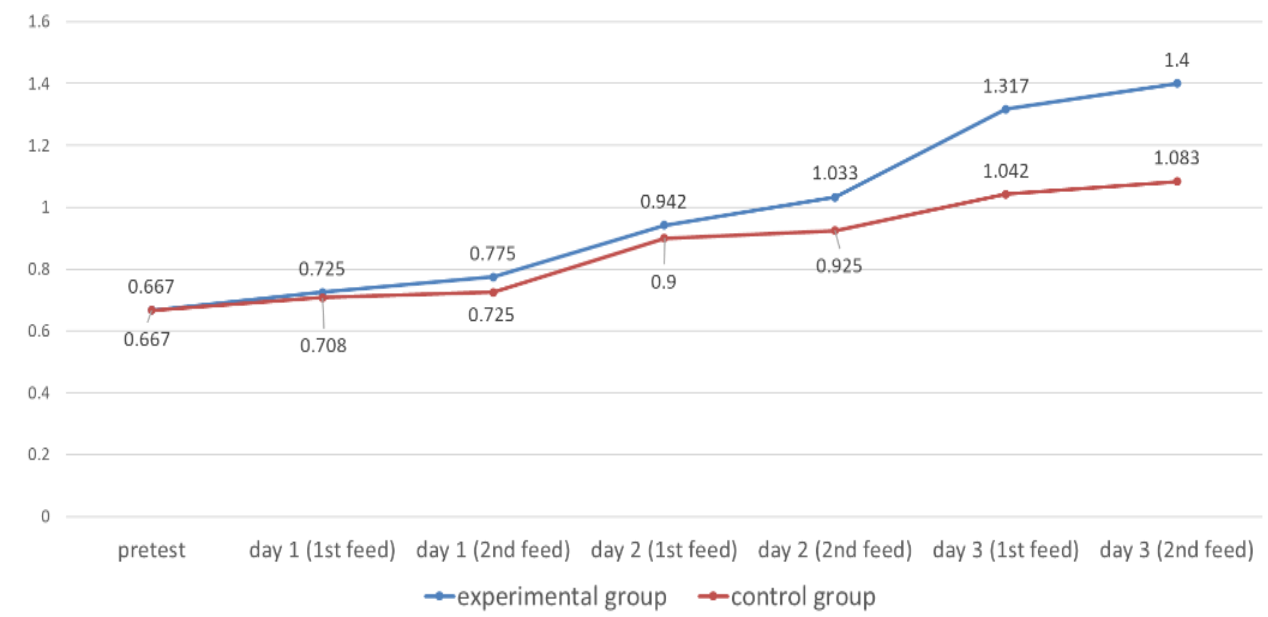

Figure 4: line diagram shows mean score of ability to coordinate swallowing in the preterm neonates in experimental and control group, $\mathrm{n}=60(\mathrm{nE}=30+\mathrm{nC}=30), \mathrm{E}=$ experimental group, $\mathrm{C}=$ control group 
Ishika Roy et.al. Effect of oromotor stimulation on sucking and feeding performance of preterm neonates admitted in neonatal care unit of selected hospital, West Bengal.

Data in the line diagram showed that mean score of ability to coordinate swallowing in both experimental and control groups have consistently increased over time but the score in experimental group is higher than that of the control group.

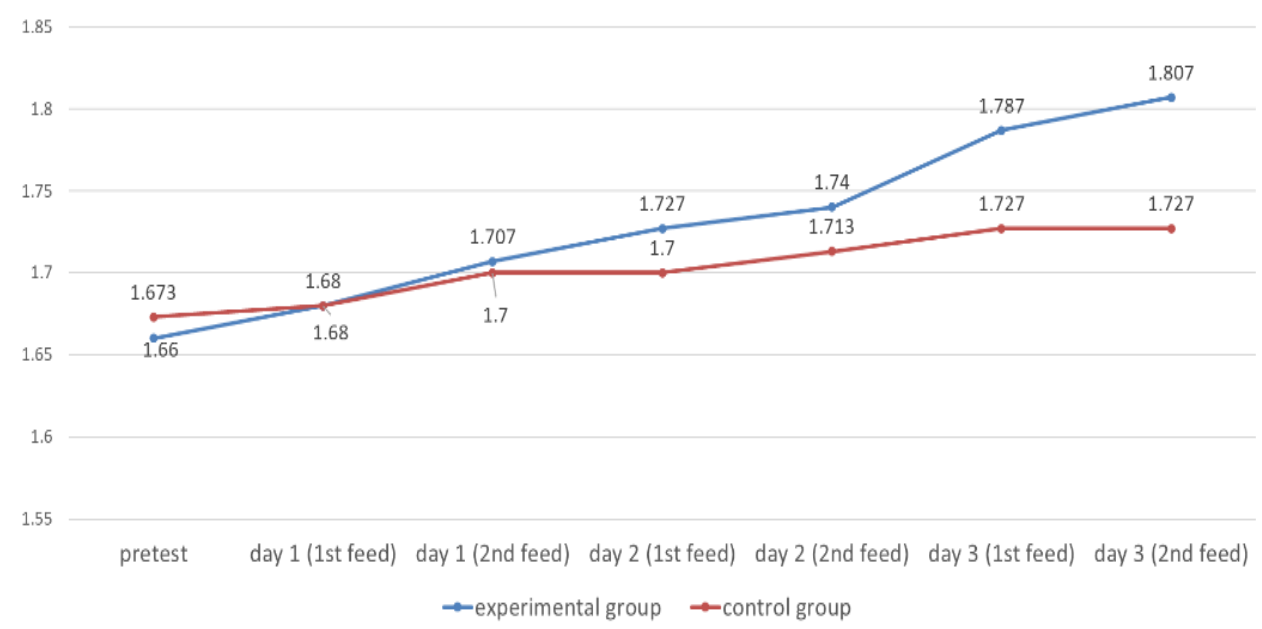

Figure 5: line diagram shows mean score of ability to maintain physiologic stability in the preterm neonates in experimental and control group, $\mathrm{n}=60(\mathrm{nE}=30+\mathrm{nC}=30), \mathrm{E}=$ experimental group, $\mathrm{C}=$ control group

Data the line diagram showed that mean score of ability to maintain physiologic stability in both experimental and control groups have consistently increased over time but the score in experimental group is little higher than that of the control group.

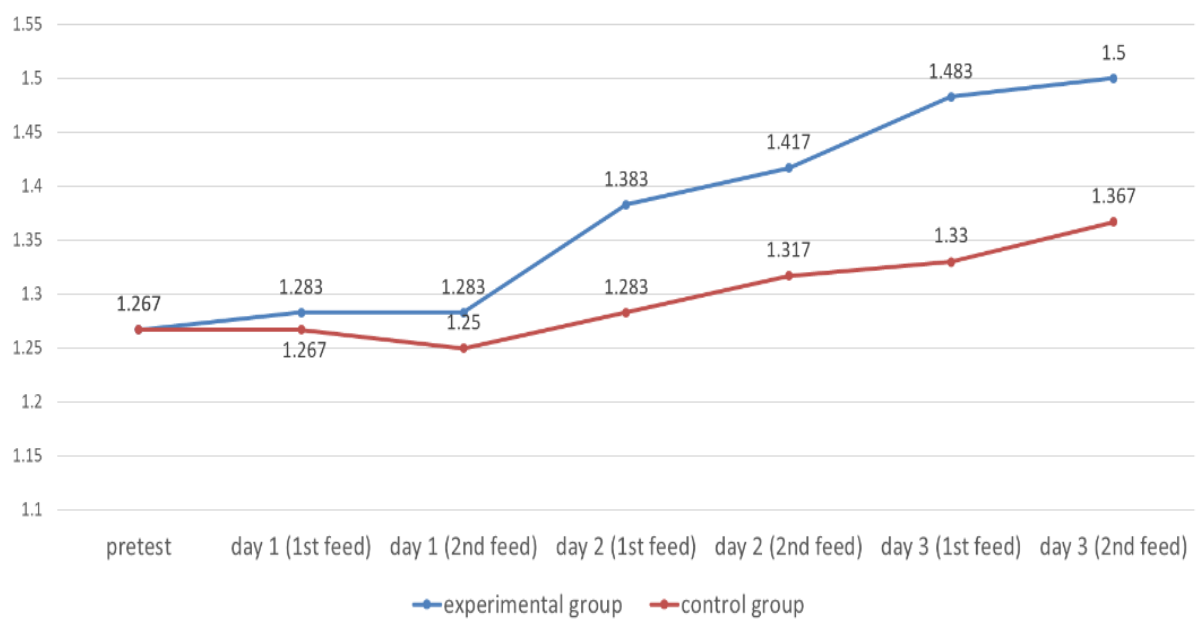

Figure 6: line diagram shows mean score of oral feeding recovery in the preterm neonates in experimental and control group $\mathbf{n}=$ $60(\mathrm{nE}=30+\mathrm{nC}=30), \mathrm{E}=$ experimental group, $\mathrm{C}=$ control group

Data the line diagram showed that mean score of ability to coordinate swallowing in both experimental and control groups have consistently increased over time but the score in experimental group is higher than that of the control group.
Table 8: Mean, SD and paired ' $t$ ' value of feeding score by EFS scoring scale in experimental group, $60(\mathrm{nE}=30+\mathrm{nC}=30), \mathrm{E}=$ experimental group, $\mathrm{C}=$ control group

\begin{tabular}{|l|l|l|l|l|}
\hline Time & Mean & SD & MD & 't' value \\
\hline Pre intervention score & 18.4 & 3.65 & 0.47 & 0.53 \\
Day 1 $\left(1^{\text {st }}\right.$ feeding) & 18.87 & 3.18 & & \\
\hline Pre intervention score & 18.4 & 3.65 & 1.17 & 1.29 \\
Day 1 $\left(2^{\text {nd }}\right.$ feeding) & 19.57 & 3.33 & & \\
\hline Pre intervention score & 18.4 & 3.65 & 3.37 & 3.56 \\
Day 2 $\left(1^{\text {st }}\right.$ feeding) & 21.77 & 3.68 & & \\
\hline Pre intervention score & 18.4 & 3.65 & 4.33 & $4.46(*)$ \\
Day 2 (2 $2^{\text {nd }}$ feeding) & 22.73 & 3.86 & & \\
\hline Pre intervention score & 18.4 & 3.65 & 7.23 & $7.18(*)$ \\
Day 3 (1 $1^{\text {st }}$ feeding) & 25.63 & 4.13 & & \\
\hline Pre intervention score & 18.4 & 3.65 & 8.3 & $8.15\left(^{*}\right)$ \\
Day 3 $\left(2^{\text {nd }}\right.$ feeding) & 26.7 & 4.21 & & \\
\hline
\end{tabular}

Table value of $t$ df (29) $=3.66, P<0.05(*)$ - Significant 
Data presented in table 8 showed that there is significant difference between the mean pre-test feeding performance score and post-test feeding performance score of preterm neonates in experimental group after receiving oromotor stimulation as measured by early feeding performance scale on day 2 , in 2 nd feeding and on day 3 , in 1 st and 2nd feeding. It can be concluded that oromotor stimulation is effective in improving the feeding performance of preterm neonates.

Table 9: Mean, SD and unpaired ' $t$ ' value of feeding score by EFS scoring scale in experimental and control group, $n=$ $60(\mathrm{nE}=30+\mathrm{nC}=30), \mathrm{E}=$ experimental group, $\mathrm{C}=$ control group

\begin{tabular}{|l|l|l|l|l|l|}
\hline Time & Group & Mean & SD & MD & 't' value \\
\hline Day 1 & Experimental group & 18.87 & 3.18 & 0.30 & 0.35 \\
$\left(1^{\text {st }}\right.$ feeding $)$ & Control group & 18.57 & 3.41 & & \\
\hline Day 1 & Experimental group & 19.57 & 3.32 & 0.87 & 0.99 \\
$\left(2^{\text {nd }}\right.$ feeding $)$ & Control group & 18.7 & 3.43 & & \\
\hline Day 2 & Experimental group & 21.77 & 3.68 & 1.5 & 1.72 \\
$\left(1^{\text {st }}\right.$ feeding $)$ & Control group & 20.27 & 3.03 & & \\
\hline Day 2 & Experimental group & 22.73 & 3.86 & 1.9 & 2.01 \\
$\left(2^{\text {nd }}\right.$ feeding $)$ & Control group & 20.83 & 3.44 & & \\
\hline Day 3 & Experimental group & 25.63 & 4.13 & 3.26 & $3.30\left(^{*}\right)$ \\
$\left(1^{\text {st }}\right.$ feeding $)$ & Control group & 22.37 & 3.53 & & \\
\hline Day 3 & Experimental group & 26.7 & 4.21 & 3.83 & $3.78\left(^{*}\right)$ \\
$\left(2^{\text {nd }}\right.$ feeding $)$ & Control group & 22.87 & 3.61 & & \\
\hline
\end{tabular}

Data presented in table 11 showed that there is significant difference between the mean post-test feeding performance score of preterm neonates in experimental group and the mean post-test feeding performance score of preterm neonates in control group as measured by early feeding performance scale on day 3 , in 1 st and 2 nd feeding. It can be concluded that oromotor stimulation is effective in improving the feeding performance of preterm neonates.

\section{DISCUSSION}

The finding of the current study showed that, mean oral feeding readiness score in both experimental and control groups have consistently increased over time but the score in experimental group is higher than that of the control group. Preterm neonates received pr efeeding oral stimulation technique had better oral feeding readiness than preterm neonates in control group. The finding of the current study is supported by the study conducted by Gennattasio et al. ${ }^{[18]}$ who conducted the study on oral feeding readiness among premature neonates and mentioned that preterm neonates in the inter vention group had better oral feeding readiness than control group.
The current study finding showed that, all preterm neonates in interventional group had high ability to coordinate oral motor functioning than the neonates in control group. This finding attributes to the fact that preterm neonates received prefeeding oral stimulation technique had higher ability to coordinate oral-motor functioning. This finding was in line with a study conducted by Bingham et al. ${ }^{[19]}$ where feeding performance of preterm neonates in the experimental group had better oralmotor coordination than preterm neonates in the control group.

In the present study it was found that preterm neonates who received prefeeding oromotor stimulation had high ability to coordinate swallowing. This finding is congruent with the study of Fucile et al. ${ }^{[7]}$ where it was found that preterm neonates who received the intervention had better ability to coordinate swallowing than preterm neonates in the control group.

The current study revealed that mean score of ability to maintain physiologic stability in both experimental and control groups have consistently increased over time but the score in experimental group is little higher than that of the control group. The result of the current study was in line with Song D et al. ${ }^{[20]}$ who conducted a 
study on effect of patterned frequencymodulated oral stimulation in preterm infants, and it was revealed in this study that the neonates received intervention had an increased physiologic stability.

The result of the present study revealed that the feeding performance of preterm infants in experimental group improved over time. On day 3 , in both 1 st and 2 nd feeding the mean post- intervention feeding score in experimental group much higher than control group. The feeding score was found to be significantly higher in the experimental group with the application of prefeeding oromotor stimulation. The study was in agreement with many authors; Lessen ${ }^{[21]}$ studied the effect of PIOMI (Premature Infant Oral Motor Intervention) on feeding progression and length of stay in preterm infants, and found that PIOMI improves oral feeding skills. Amer ${ }^{[22]}$ conducted a study on the effect of prefeeding oral stimulation on preterm neonates' feeding performance, and found that prefeeding oral stimulation improve the feeding skills preterm neonates. Lau et al. ${ }^{[23]}$ who conducted a study about impact of non-nutritive oral motor stimulation on oral feeding skills of preterm infants, revealed that non-nutritive oral motor stimulation enhances the maturation of neonates' oral feeding skills.

The result of the present study revealed that the sucking performance of preterm infants in experimental group improved over time. On day 3, 2nd feeding $36.67 \%$ neonates in experimental group had good sucking performance whereas only $6.66 \%$ neonates in control group had good sucking performance. On day 3 , in both 1 st and 2 nd feeding the mean post- intervention sucking score in experimental group was higher than control group. The sucking score was found to be significantly higher in the experimental group with the application of prefeeding oromotor stimulation. These findings were congruent with the study results of a study done by Tharwat et al. ${ }^{[24]}$ who found the neonates in experimental group had improved sucking skill than neonates in control group. It is also congruent with the study conducted by Moura et al. [11] who found oromotor stimulation is effective in improving the sucking frequency, Latch scores, and fastens the transition from spoon-feeding to breastfeeding.

\section{Nursing implications:}

As a large number of neonates suffers from feeding deficiencies and nurses are the primary caregiver of neonates admitted in neonatal care units so they can play a pivotal role in improving oral feeding performance of preterm neonates through prefeeding oral motor stimulation, and reduce their duration of gavage feeding.

Nurse educator has a great role in teaching nursing students. Nursing students must understand that the necessity of early oral feeding and eventually breastfeeding in neonates. Nursing students must learn the proper technique of oromotor stimulation so they can also provide oromotor stimulation to the preterm neonates whenever they are working in neonatal care units.

Nurse administrators play a vital role in encouraging nurses about the need of providing oromotor stimulation to the neonates admitted in neonatal care units. Nurse administrators will carry out proper evaluation to monitor that the oromotor stimulation is being provided to the preterm neonates routinely and in appropriate technique. They should incorporate oromotor stimulation as a routine care in neonatal care units and should develop a protocol or standard guideline for the care.

This study covered an important nursing care aspect but this study has some limitations too; those are: Firstly, small sample size, secondly oromotor stimulation was provided to the preterm neonates for only three consecutive days. The total number of days required for the preterm neonates to start full breastfeeding was not considered.

On the basis of findings, the following recommendations are offered for the future research: 
A study can be conducted to assess the effect of oral stimulation on transition from tube to oral feeding in preterm neonates.

A comparative study can also be done to assess the effect of oral stimulation given by nurses versus mothers on feeding performance of preterm neonates.

\section{CONCLUSION}

On the basis of the findings of the present study it can be concluded that oromotor stimulation is effective in enhancing the sucking and feeding performance of preterm neonates. Providing oromotor stimulation to the preterm neonates during gavage feeding proved to be beneficial in improving the sucking ability and oral feeding performance of preterm neonates.

\section{Acknowledgement: None}

\section{Conflict of Interest: None}

\section{Source of Funding: None}

\section{Ethical Approval: Approved}

\section{REFERENCES}

1. World Health Organization. Preterm birth, Country, Regional and Global Estimates. Geneva, Switzerland: World Health Organization; 2018.Available from https://www.who.int

2. Amaizu N, Shulman RJ, Schanler RJ, et al. Maturation of oral feeding skills in preterm infants. Acta Paediatr. 2008 Jan; 97(1): 6167.

3. Zelda G, O'Donnell CP, Walshe M. Oral stimulation for promoting oral feeding in preterm infants. Cochrane Database Syst Rev. 2016 Sep; 2016(9):

4. Hill AS, Kurkowski TB, Garcia J. Oral support measures used in feeding the preterm infant. Nurs Res. 2000 Jan; 49(1): 2-10.

5. Arvedson J, Clark H, Lazarus C, et al. Evidence-based systematic review: effects of oral motor interventions on feeding and swallowing in preterm infants. Am J Speech Lang Pathol. 2010 Nov; 19(4): 321-40.
6. Pareshkumar A, Thakkar H, Das RR, Thakkar P, et al. Effect of oral stimulation on feeding performance and weight gain in preterm neonates: a randomised controlled trial, Paediatrics and International Child Health. 2018 Jan; 38(3): 181-186.

7. Lau C, Fucile S, Gisel EG. Impact of nonnutritive oral motor stimulation and infant massage therapy on oral feeding skills of preterm infants. Journal of NeonatalPerinatal Medicine. 2012 Apr; 5(4): 311317.

8. Pimenta HP, Moreira ME, Rocha AD, et al. Effects of non-nutritive sucking and oral stimulation on breastfeeding rates for preterm, low birth weight infants: a randomized clinical trial. J Pediatr (Rio J). 2008; 84: 423-427.

9. Bala P, Kaur R, MukhopadhyayK, et al. Oromotor stimulation for transition from gavage to full oral feeding in preterm neonates: A Randomized controlled trial. Indian Pediatr. 2016 Jan; 53(1): 36-38.

10. Lyu TC, Zhang Y, et al. The effect of an early oral stimulation program on oral feeding of preterm infants. International Journal of Nursing Sciences. 2014 Mar; 1(1): 42-47.

11. Moura LTL, Tolentino GM, Costa TLS, et al. Action of speech therapy on early stimulation of non-nutritive sucking in preterm new born. Rev CEFAC. 2009; 11(3): 448-56.

12. Bauer MA, Yamamoto RCC, Weinmann ARM, et al. Evaluation of sensory-motororal stimulation in the transition from gastric tube to full oral feeding in preterm newborns. Rev Bras Saude Mater Infant. 2009; 9(4): 429-34.

13. Calado DFB, Souza R. Preterm newborns speech therapy: oromotor stimulation and non-nutritive sucking. Rev CEFAC. 2012; 14(1): 176-81.

14. Barlow SM, Finan DS, Lee J, et al. Synthetic orocutaneous stimulation entrains preterm infants with feeding difficulties to suck. J Perinatol. 2008 Aug; 28(8): 541 -8.

15. Bingham PM, Ashikaga T, Abbasi S. Prospective study of non-nutritive sucking and feeding skills in premature infants. Arch Dis Child Fetal Neonatal Ed. 2010 May; 95(3): F194-200.

16. Liu Y, Chen YL, et al. Early oral-motor management on feeding performance in premature neonates. Journal of the 
Ishika Roy et.al. Effect of oromotor stimulation on sucking and feeding performance of preterm neonates admitted in neonatal care unit of selected hospital, West Bengal.

Formosan Medical Association. 2013 Mar; 112(3): 161-164.

17. Neiva FCB, Leone CR, Leone C. Validation of a non nutritive sucking score system for oral feeding in preterm newborns. Acta Paediatr. 2008; 97(10): 1370-5.

18. Gennattasio A, Perri E, Baranek, et al. Oral feeding readiness assessment in premature infants. MCN: The American Journal of Maternal/Child Nursing. 2015; 40(2): 96104.

19. Bingham P, Ashikaga T, Abbasi S. Relationship of neonatal oral motor assessment scale to feeding performance of premature infants. Journal of Neonatal Nursing. 2012; 18(1): 30-36.

20. Song D, Jegatheesan $P$, Nafday $S$, et al. (2019) Patterned frequency-modulated oral stimulation in preterm infants: A multicenter randomized controlled trial. PLoS ONE 14(2): e0212675.

21. Lessen B. Effect of premature infant oral motor intervention on feeding progression and length of stay in preterm infants. Adv Neonatal Care. 2011; 11(2): 129-139.
22. Amer H. Effect of prefeeding oral stimulation program on feeding performance of pretrerm infants, Pediatric department, Faculty of nursing, Cairo University. Journal of Biology, Agriculture and Healthcare 2015; 28(4): 122-126.

23. Fucile S, Gisel E, Lau C, et al. Oral and non-oral sensorimotor interventions facilitate suck-swallow-respiration functions and their coordination in preterm infants. Early Hum Dev. 2012; 88: 345-350.

24. Tharwat H, El-Shahat M, ELSamman GA, et al. Early Feeding Skills among Preterm Neonates Received Verses Not Received Prefeeding Oral Stimulation Technique In Neonatal Intensive Care Units In Ismailia City. Journal of Nursing and Health Science. 2018 Jul-Aug; 7(4): 67-75.

How to cite this article: Roy I, Jana M. Effect of oromotor stimulation on sucking and feeding performance of preterm neonates admitted in neonatal care unit of selected hospital, West Bengal. International Journal of Research and Review. 2021; 8(8): 40-50. DOI: https://doi.org/ 10.52403/ijrr.20210808 